\author{
A. Komorek ${ }^{1}$, D. Grygiel ${ }^{1}$, R. Bieńczak ${ }^{1}$, J. Godzimirski ${ }^{2}$ \\ ${ }^{1}$ Faculty of Aviation Polish Air Force Academy, Dęblin, Poland \\ komman@op.pl \\ ${ }^{2}$ Faculty of Mechatronics and Aviation, Military University of Technology, Warsaw, Poland
}

\title{
THE POSSIBILITY OF A VISUAL ANALYSIS OF THE FAILURE OF BUTT ADHESIVE JOINTS MADE WITH DIFFERENT GLUES
}

\begin{abstract}
The results of conducted by the authors of the article numerical analyzes, indicate the importance of normal stresses, perpendicular to the adhesive joint, during the impact destruction of block adhesive samples. This kind of stresses are responsible for the occurrence of tearing or chipping in a joint. The very significant influence of adhesion in the impact-bonded adhesive joint was the reason for testing this parameter in joints made with adhesives with different Young's modulus. It was assumed that adhesives differing in stiffness will have different adhesive properties, which should affect the impact strength of the adhesive joints. It was also assumed that the adhesion in the joint can be assessed by analyzing the surfaces of joint damage. Cylindrical butt joints connected with various adhesives were used to carry out the tests, in which they were loaded on tear-off. The nature of tested joints damage was usually cohesive or cohesive-adhesive. The assessment of the nature of joint damage allowed to determine whether they were the result of the loss of cohesion by the adhesive (cohesive damage) or the effect of poor adhesion between the hardened joint and adherends (adhesive damage). The assessment of the nature of the destruction was carried out by three methods: visual, using an optical microscope and using an electron microscope. As a result of the carried out observations, it was found that the visual method is the least useful and not very reliable, especially in the case of transparent or low-contrast in relation to the glued material joints. The use of electron microscope allows to obtain the most reliable results, however, the possible magnification is too large and the assessment of the entire weld fracture is difficult because it does not fit in the field of observation. Observations conducted using optical microscopy at a slight magnification (5-10 times), in most cases allow to determine the nature of the destruction to a satisfactory degree, with limitations such as in the visual method.
\end{abstract}

Keywords: adhesive joint, butt sample, visual analysis

\section{INTRODUCTION}

Adhesive joints are more and more commonly used in various industrial branches, not only in the transport industry [1,2] but also in the production of daily use articles [3]. The growing popularity of these joints is associated with their properties, which are frequently inaccessible for other types of joints [4]. It is worth noting that glue joints are also increasingly made with several types of adhesives (mixed joints) [5] as well as being used in hybrid connections with classical joints (glued-welded, glued-riveted, etc.) [6, 7]. During the testing of adhesive joints carried out by the authors of this paper, it was noted that the impact 
strength of adhesive block samples used to determine the comparative impact strength of adhesives is significantly dependent upon the adhesive strength of glued joints. This is due to the fact that in this type of impact loaded joints (Fig. 1), the highest values are obtained by normal stresses, which are perpendicular to the connected surfaces, and these stresses are typically associated with the adhesive strength of joints.

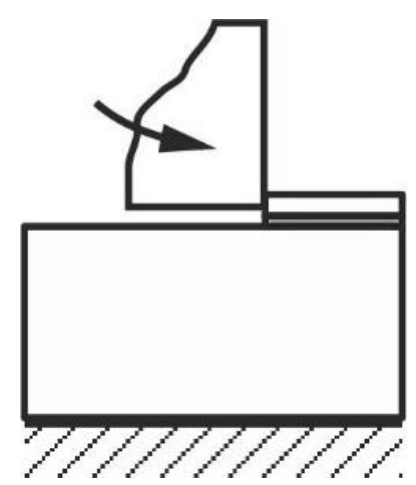

Fig. 1. Diagram of examining impact strength in block samples

This was found in both static [8] and dynamic numerical analyses of adhesive block joints $[9,10]$. The results of the analyses indicate the significance of normal stresses, perpendicular to the glued joint; the stresses are responsible for the occurrence of tear-off or chipping in the joint.

It is also worth noticing that with the height of applying the load over the joint equal to $0.8 \mathrm{~mm}$ (height being in accordance with the requirements of Standard PN-EN ISO 9653) the normal stress values are close to the tangential static values, which seem to prevail with the assumed manner of the load application. While increasing the distance between the impactor and the joint, the value of the tangential stresses falls and of the normal ones, it rises (Fig. 2).

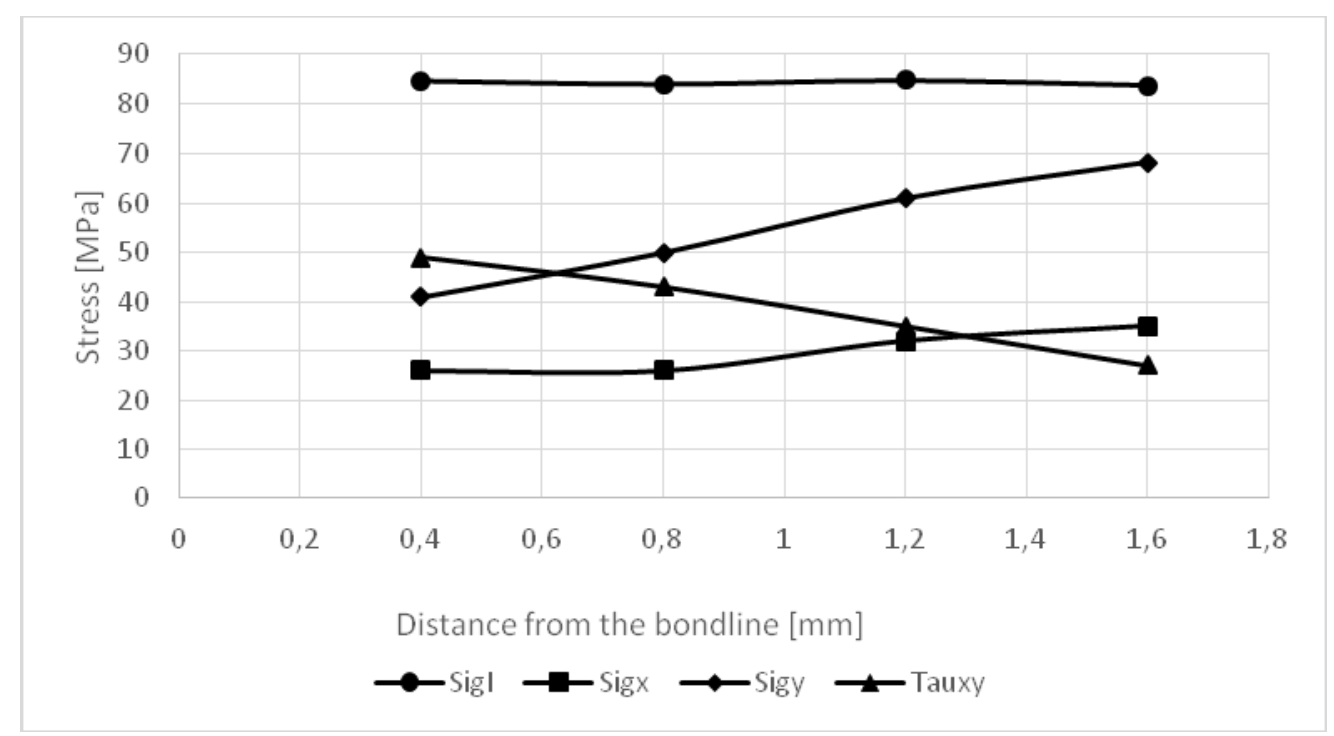

Fig. 2. The dependence between stresses in joints and the distance of the impactor's edge to the surface of the joint ( $\sigma \mathrm{l}$ - Max Principal Stresses, $\sigma \mathrm{x}$ - normal stresses perpendicular to the surface of the joint, Txy- tangential stresses in the direction of impact loading) 
This is due to increasing the value of the bending moment of the impacted upper element. A highly significant effect of adhesion in the adhesive joint resulted in conducting an investigation of this parameter in adhesive joints made with different glues, of different coefficients of the elastic modulus. It was assumed that such glues may be characterized by different adhesive properties, which should affect the impact strength of adhesive joints, made with them.

\section{EXPERIMENTAL}

In the study the authors used butt adhesive joints, in which the joints are loaded for tearoff. In such a joint, the glue layers which are immediately adjacent to the bonded surfaces cannot be subject to regular deformation in the joint plane (radial). The remainder of the joint layers undergo such deformations with loading combined with axial forces. The walls of the adhesive joints of butt connections become concave in their shape (Fig. 3), which proves the occurrence of tangential stresses [11].

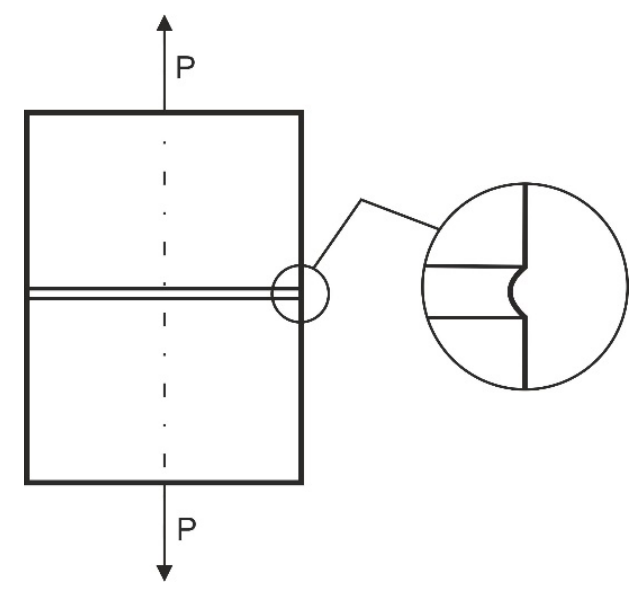

Fig. 3. Model of an adhesive joint impact loaded for tear-off [3]

Using the FEM, the authors determined the distribution of stresses in the joint of such connections [12] and assessed their influence on the strength of the joint. The analysis of the stress distribution in the adhesive joint depicted in Fig. 4 leads to a conclusion that the maximum tangential stresses occurring in the joint are smaller, by an order of magnitude smaller, than in case of normal stresses and exert hardly any effect on the extent of the joint subjected to tension. 


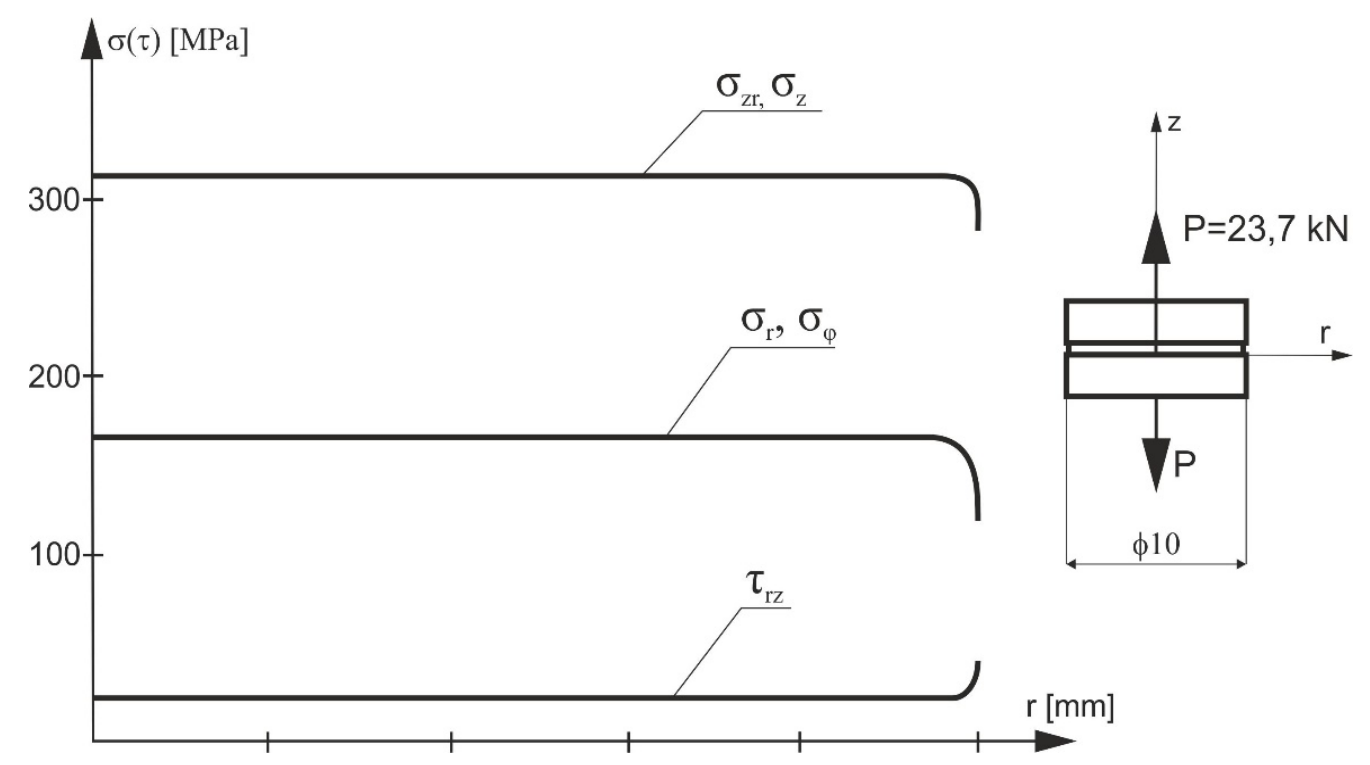

Fig. 4. Stress distribution in the joint layer which is immediately adjacent to the butt connection, axiallysymmetrically extended : or, oof $\sigma, \varphi$-normal stress, orz -reduced stress, trz -tangential stress, $r$ - radius of the joint [4]

Elements of samples made with steel S235 or the aluminium alloy 2017A were bonded with 6 epoxy adhesives: Epidian 57 with Z1 hardener of 10:1, Loctite EA adhesives: 9450, 9455, 9480, 9492, 9464, and one hybrid adhesive (cyanoacrylate-epoxy) - Loctite 4090. The catalogue values of elasticity modulus of adhesives have been presented in Table 1.

Table 1. Young's modulus of adhesives used in research

\begin{tabular}{|l|c|c|c|c|c|c|c|}
\hline & \multicolumn{7}{|c|}{ Name of glue } \\
\cline { 2 - 8 } & $\begin{array}{c}\text { Epidian } \\
57 / \text { Z1 }\end{array}$ & $\begin{array}{c}\text { Loctite } \\
\text { EA 9450 }\end{array}$ & $\begin{array}{c}\text { Loctite } \\
\text { EA 9455 }\end{array}$ & $\begin{array}{c}\text { Loctite } \\
\text { EA 9464 }\end{array}$ & $\begin{array}{c}\text { Loctite } \\
\text { EA 9480 }\end{array}$ & $\begin{array}{c}\text { Loctite } \\
\text { EA 9492 }\end{array}$ & $\begin{array}{c}\text { Loctite } \\
4090\end{array}$ \\
\hline $\begin{array}{l}\text { Young's } \\
\text { modulus } \\
{[\mathrm{MPa}]}\end{array}$ & 1850 & 1025 & 60 & 700 & 4400 & 6700 & 565 \\
\hline
\end{tabular}

The surfaces for joining were prepared by means of abrasive blasting, and the abrasive agent was copper slag. Due to the conducted treatment, the authors obtained the mean arithmetic profile deviation from the average line $\mathrm{R}_{\mathrm{a}}=3.90 \mu \mathrm{m}$. Before bonding the surfaces of the samples were degreased by means of gasoline extraction, which was evaporated in the chamber of the laboratory dryer. After applying the adhesive onto the bonded surfaces, the elements of the samples were assembled and left to harden for a period of 7 days. The obtained average thickness of the joints was equal to $g_{k}=0.05 \mathrm{~mm}$. Each series included 5 specimens. Prior to the examination, the authors performed an inspection by removing the bond excess. Due to the need to obtain the load alignment, the research used self-aligning brackets and samples which were dedicated to them (Fig. 5). 


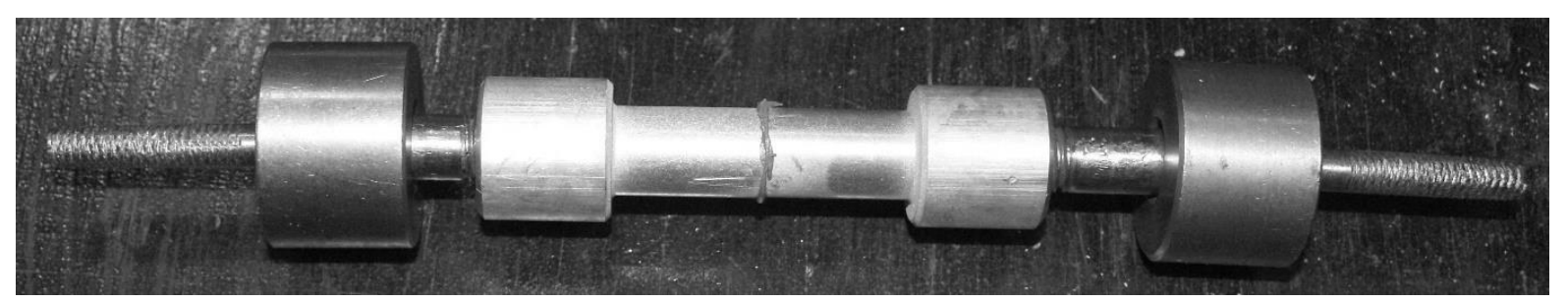

Fig. 5. The butt joint prepared for testing

The obtained findings have been presented in Fig. 6 .

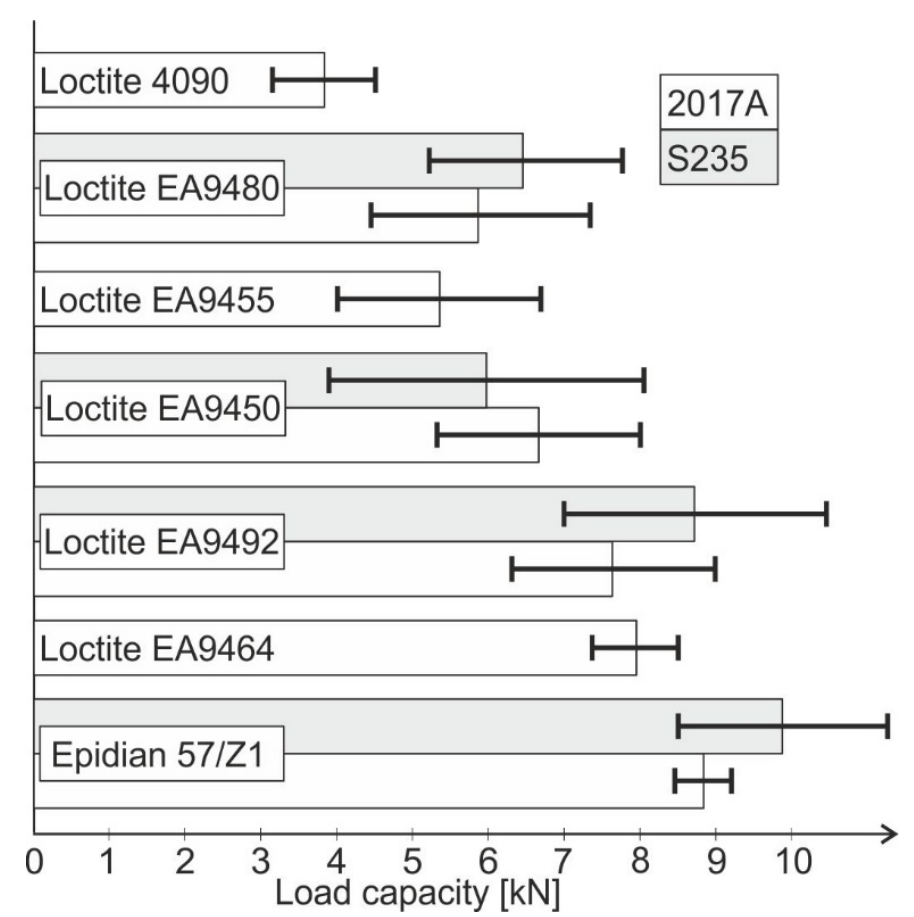

Fig. 6. The destructive force of the samples made with aluminium alloy 2017A or steel S235 adherends joined with different adhesives

The highest destructive force was obtained with Epidian 57/Z1 glue, regardless of the type of the bonded material. The lowest value of the destructive force was registered for joints made with hybrid glue. With the applied manner of preparing the surface of the adherends, the higher average strength was characterised by duralumin elements (with the exception of Loctite EA9480), however the large discrepancy among the findings does not allow making a clear comparison of the obtained results. The lack of a clear difference between the destructive force of steel or duralumin joints points to similar adhesive properties of the joined materials, undergoing abrasive blasting or cohesive damage of joints, which the authors attempted at proving in the examination of failures of the investigated joints. 


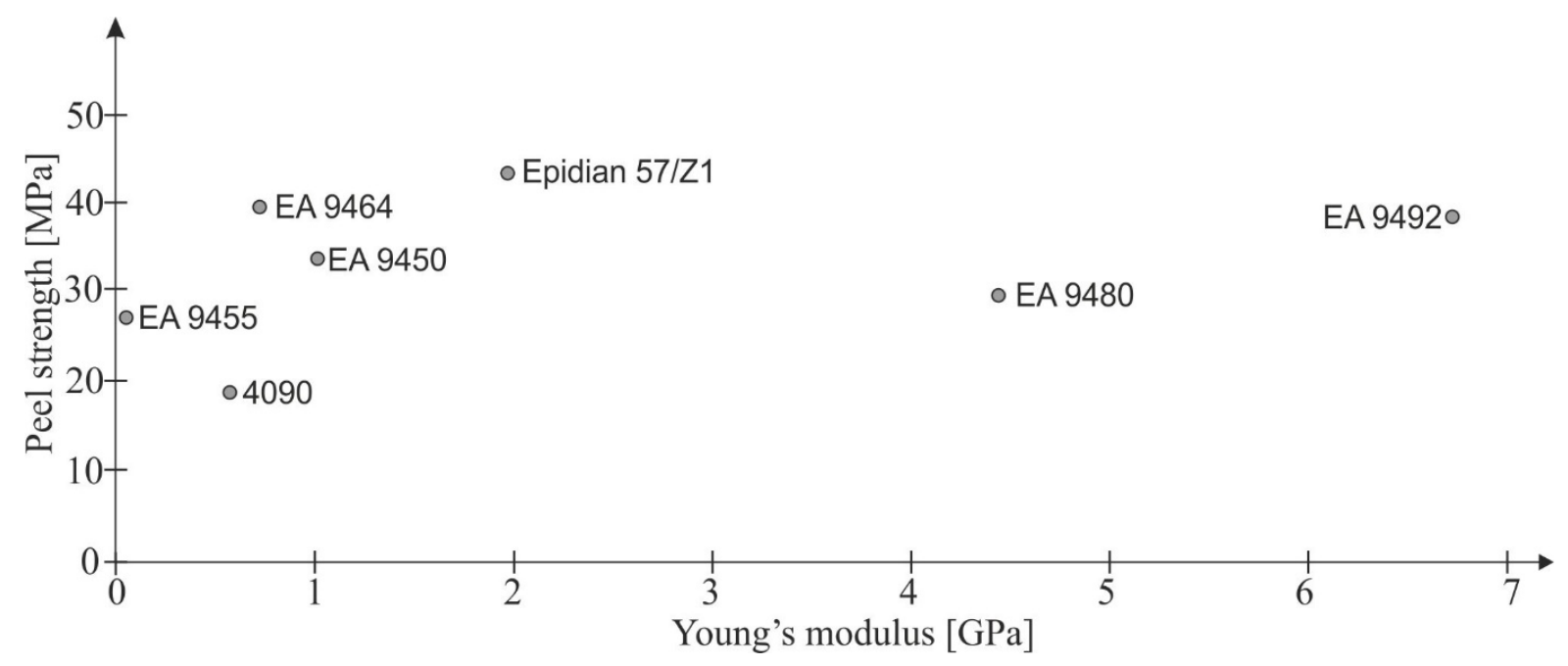

Fig. 7. Peel strength of the butt joints made of the aluminium alloy $2017 \mathrm{~A}$ and Young's modulus of the examined adhesives

The generalized diagram, as seen in Fig. 7, points to the lack of a relationship between the peel strength of butt joints and the elasticity modulus of the adhesive, therefore the value of Young's modulus of the glue cannot be used as a basis for predicting the peel strength of butt joints.

The analysis of the nature of the damage was conducted with three methods: a visual inspection $[13,14]$, with an optical microscope $[15,16]$ and with often used $[17,18]$ electron microscope. The visual analysis made with the naked eye, due to a small thickness of the adhesive joint and low contrast with a metal or transparency of certain adhesives is, in a number of cases, hampered and does not prove certain as for the nature of the damage (Fig. 8). Nevertheless, it appears that most of the damage is cohesive in its character, with little (several per cent) share of adhesive damage.

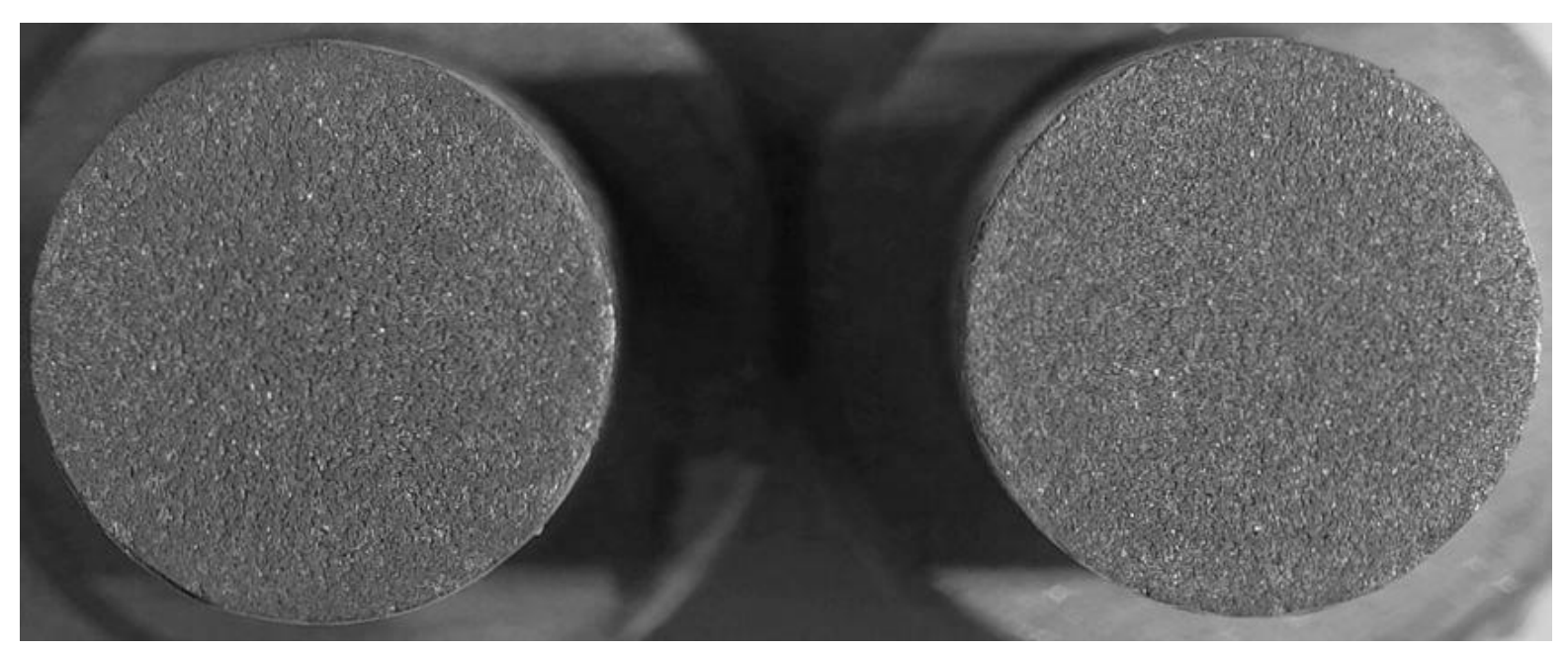

Fig.8. Failure of the aluminium-alloy 2017A elements made of transparent adhesive Loctite EA 9455, inspected visually 
The exception is joints made of adhesive Loctite 4090, where, regardless of the glued material, in the case of a few samples, one can observe traces indicating lack of bonding of glue layers applied on all the bonded elements (Fig. 9).
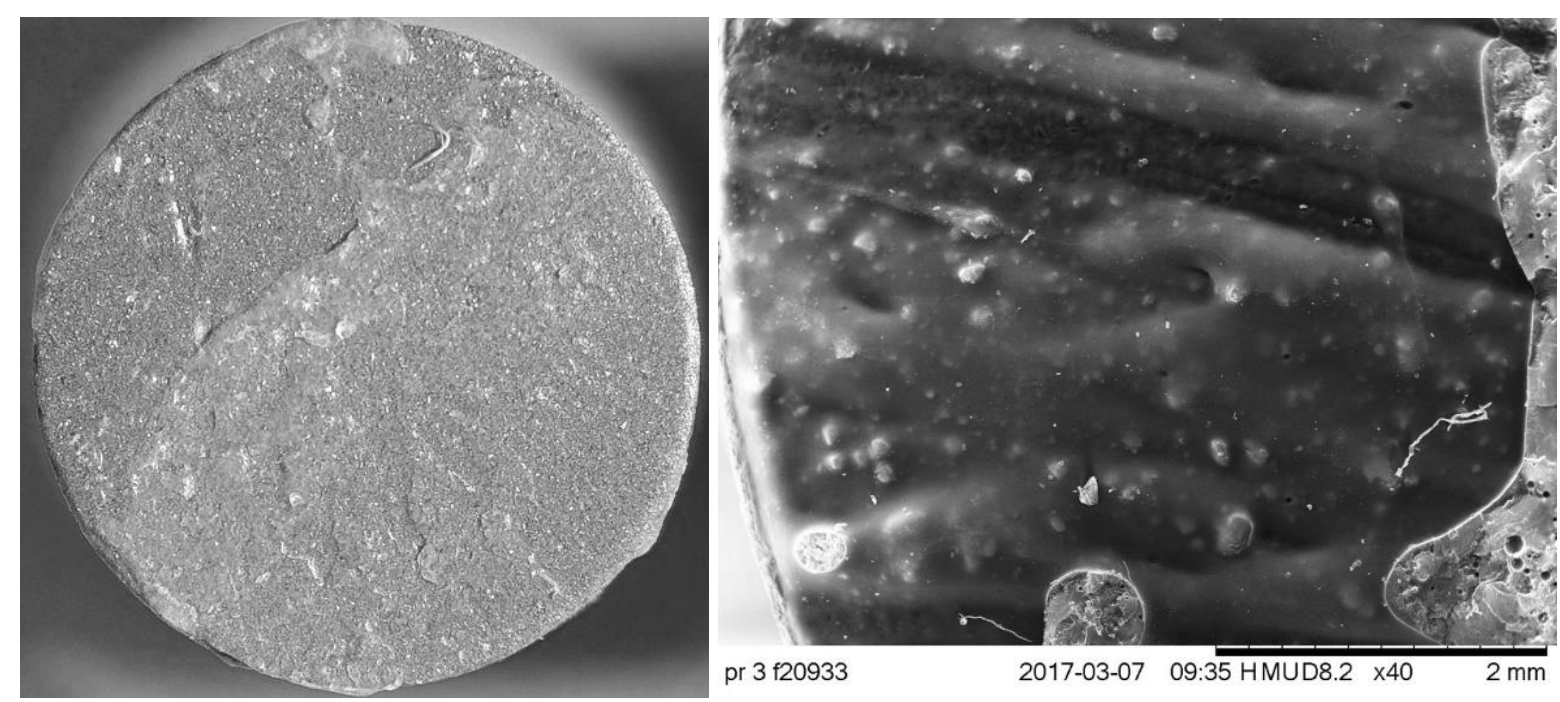

Fig. 9. Failure of the steel s235 joint, made with the adhesive Loctite 4090, a) optical microscope, Magn. x7.5, b) electron microscope. Magn. x40

The damage is not adhesive in its character, resulting from very rapid curing of the joint, made with this adhesive.

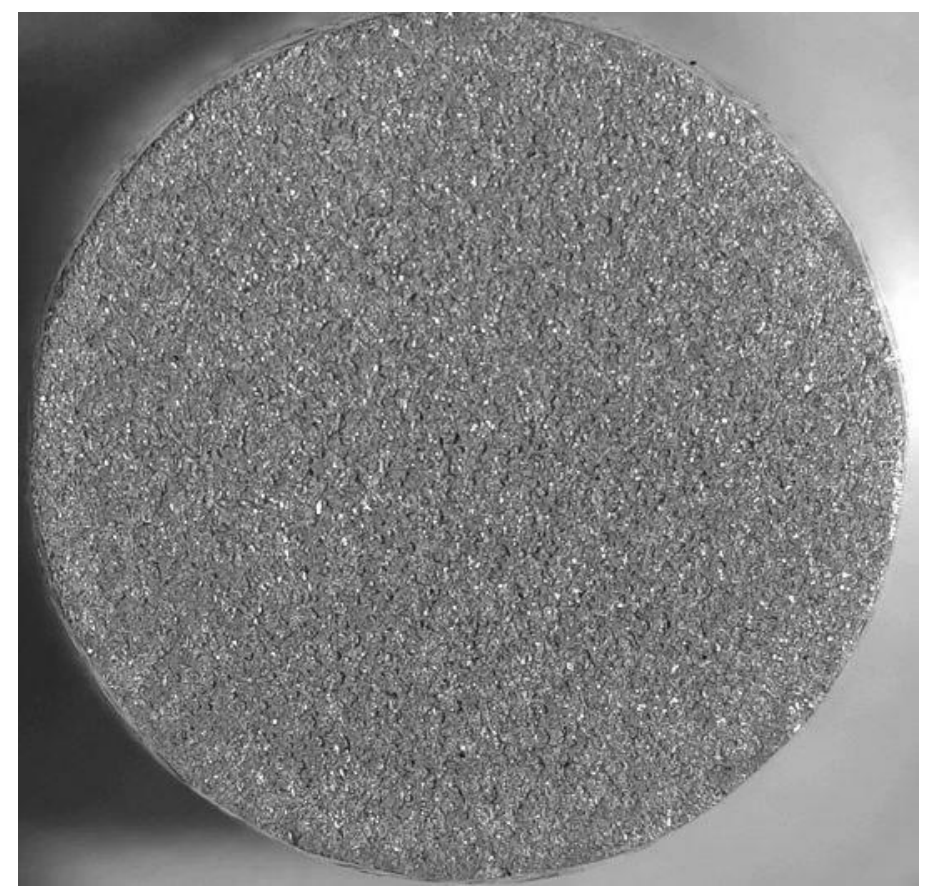

Fig. 10. Failure of the aluminium-alloy 2017A elements made with Loctite EA 9455. Optical microscope. Magn. x7.5 
Observations of failures using an optical microscope give much more reliable results (Fig. 10), however even in this case, in some areas it was difficult to find definitely the presence of residues of glue on the bonded elements. The observations made by optical microscope, on the whole, confirm conclusions stemming from visual inspections.

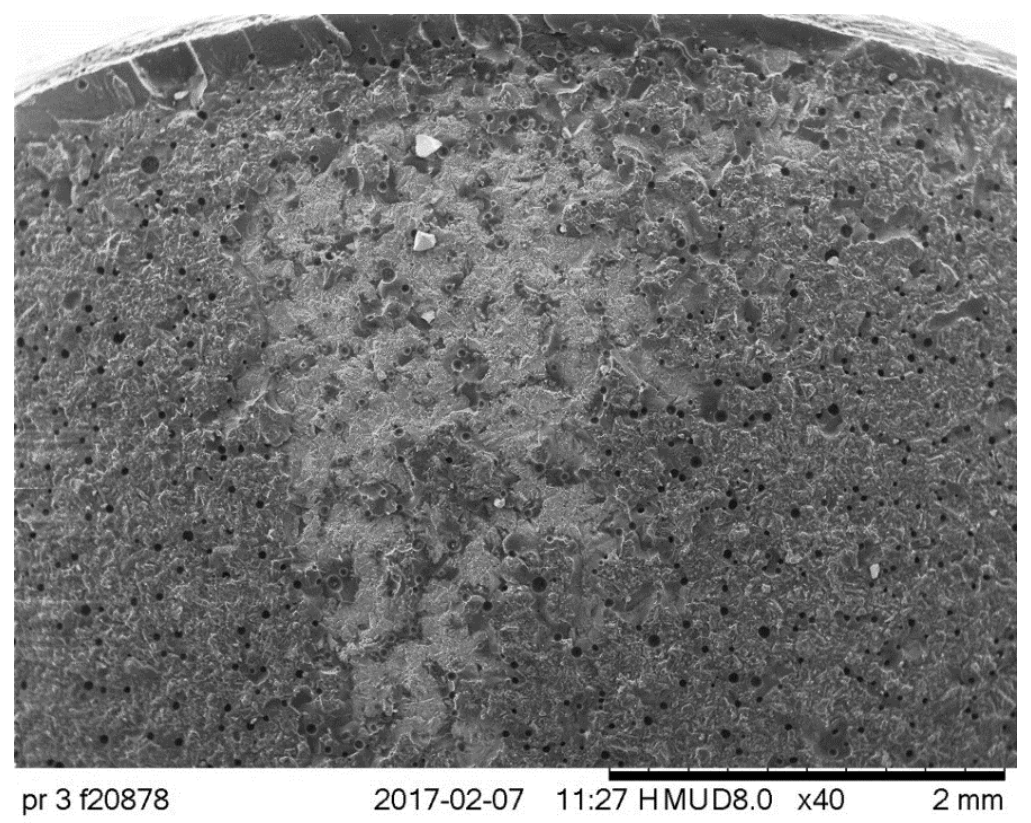

Fig. 11. Failure of the aluminium-alloy 2017A elements made with Loctite EA 9455.

Optical microscope. Magn. x 40

The observations with the use of an electron microscope confirm the dominant, cohesive nature of the damage (Fig. 11), making it possible to clarify the uncertainties. However, it should be noted that in the areas considered as adhesive damage in the optical methods, it is also possible to notice glue residues, thus it seems that when assessing the nature of the damage of the joint, one also needs to specify the manner of conducting the observation and the used magnification.

\section{CONCLUSIONS}

1. The determination of the nature of the damage of the adhesive joint based on visual inspections is often unreliable due to the difficulty in identifying the glue residue on the connected surfaces, especially in the case of a small thickness of the joint $(0.01-0.05$ $\mathrm{mm}$ ) and low contrast between the adhesive and the bonded material. In case of a good contrast, visual inspections may prove insufficient to determine the nature of the damage of the adhesive joint.

2. Observations made at low magnification (5-10 times) allow gaining greater certainty as for the glue residue on boned elements than in the case of the visual method, however, the thickness of the joint, glue contrast and the connected materials as well as the lighting of the observed surfaces significantly affect the quality of the assessment. 
3. The analysis of the nature of the damage using an electron microscope provides the greatest amount of information. Moreover, they are the best quality among the used methods. However, in order to make an evaluation with this method, it is necessary to prepare them dimensionally, which may turn them into a single use samples. In the case of samples used for testing, this may be difficult to accept.

4. When planning observations of the nature of the damage, the possibility of using contrast adhesives in relation to the adherends should be taken into consideration.

\section{REFERENCES}

1. Banea M. D. da Silva L.F.M.: The effect of temperature on the mechanical properties of adhesives for the automotive industry, Proc. IMechE Vol. 224 Part L: J. Materials: Design and Applications (2010) 51-62.

2. Jethwa J.K., Kinloch A.J.: The fatigue and durability behaviour of automotive adhesives. Part I: Fracture Mechanics Tests, The Journal of Adhesion, 61(1-4) (1997) 71-95.

3. Paiva Rosa M.M., António Carlos A.C., da Silva Lucas F.M.: Optimal design of adhesive composition in footwear industry based on creep rate minimization, International Journal of Advanced Manufacturing Technology 84(9-12) (2016) 2097-2111.

4. Skeist I. (ed.), Handbook of Adhesives, Springer, Berlin, 2011.

5. Broughton J.G, Fitton M.D.: Science of Mixed-Adhesive Joints. [In] Hybrid Adhesive Joints Advanced Structured Materials book series, (2011) 257-281.

6. Sadowski T., Golewski P., Zarzeka-Raczkowska E.: Damage and failure processes of hybrid joints: Adhesive bonded aluminium plates reinforced by rivets, Computational Materials Science, 50(4) (2011) 1256-1262.

7. Rośkowicz, M., Rożek, M.: Analiza trwałości zmęczeniowej połączeń mechanicznych i klejowomechanicznych, Technologia i Automatyzacja Montażu, 2 (2013) 16-19.

8. Adams R.D., Harris J.A.: A critical assessment of the block impact test for measuring the impact strength of adhesive bonds, International Journal of Adhesion and Adhesives, 16(2) (1996) 61-71.

9. Komorek A., Godzimirski J., Pietras A.: Numerical Analysis of Impact Loading of Adhesive Joints, Advances in Materials Science and Engineering vol. 2017 (2017), 10 pages, doi.org/10.1155/2017/5941086

10. The experimental investigation and preliminary dynamic numerical analysis of the effect of sample geometry upon the test results of impact loading of adhesive bonds. Komorek A., Godzimirski J., Pietras A., Proceedings of the $7^{\text {th }}$ International Conference on Mechanics and Materials in Design, FEUP-INEGI 2017, (2017) 1013-1014.

11. Godzimirski J., Kozakiewicz J., Łunarski J., Zielecki W.: Konstrukcyjne połączenia klejowe elementów metalowych w budowie maszyn, Oficyna Wydawnicza Politechniki Rzeszowskiej, Rzeszów, 1997.

12. Godzimirski J.: Analiza wytrzymałości połączeń klejowych elementów metalowych obciążonych statycznie. Rozprawa habilitacyjna. WAT, Warszawa (1988).

13. Rudawska A., Stančeková D., Brzęczek J.: The visual method in quality assessment of single-lap adhesive joints Advances in Science and Technology Research Journal 10(31) (2016) 109-118. doi.org/10.12913/22998624/64066. 
14. Barra G., Vertuccio L., Vietri U., Naddeo C., Hadavinia H., Guadagno L.: Toughening of Epoxy Adhesives by Combined Interaction of Carbon Nanotubes and Silsesquioxanes, Materials 10(10) (2017) 1131. doi:10.3390/ma10101131.

15. da Silva L.F.M., Adams R.D., Gibbs M.: Manufacture of adhesive joints and bulk specimens with high-temperature adhesives, International Journal of Adhesion \& Adhesives, 24 (2004) 69-83.

16. Chang, L., Guo, W., and Tang, Q.: Assessing the tensile shear strength and interfacial bonding mechanism of poplar plywood with high-density polyethylene films as adhesive, BioResouces, 12(1) (2017) 571-585.

17. Łępicka M., Grądzka-Dahlke M.: Surface Analysis for Signs of Corrosion of Fixed Orthodontic Appliances Used In Vivo, Advances in Material Science, 16(3) (2016) 5-14.

18. Rokosz K., Hryniewicz T., Dudek Ł., et al.. SEM And EDS Analysis Of Nitinol Surfaces Treated By Plasma Electrolytic Oxidation. Advances in Materials Science, 15(3) (2015) 41-47 doi:10.1515/adms-2015-0014. 